Reviu Akuntansi dan Bisnis Indonesia, Vol. 5 No. 1, Hlm: 79-90, Juli 2021

Website: http://journal.umy.ac.id/index.php/rab

\title{
Pengaruh Appearance dan Individualism terhadap Penggunaan E-filing dengan Kepuasan Pengguna sebagai Variabel Intervening (Studi Empiris pada Wajib Pajak UMKM di Provinsi Bengkulu)
}

Afrizal Tahar; Alya Jilan Sabiqoh *; Nisa Ilmiati; Demelia Wulandari

Program Studi Akuntansi Universitas Muhammadiyah Yogyakarta

\begin{tabular}{l}
\hline I N F O A R T I K E L \\
\hline Kata Kunci: \\
E-Filing; Pajak; Wajib \\
Pajak UMKM; \\
Appearance; Individualism; \\
Kepuasan Pengguna \\
Jenis Artikel: \\
Penelitian Empiris \\
Korespondensi: \\
alya.jilan.feb17@mail.umy.ac.id \\
Proses Artikel: \\
Diterima 3 Mei 2021 \\
Review 1 Juni 2021 \\
Revisi 25 Juni 2021 \\
Diterbitkan 1 Juli 2021 \\
Sitasi: \\
Tahar, A., Sabiqoh, A.J., \\
Ilmiati, N., \& Wulandari, D. \\
(2021). Pengaruh \\
Appearance dan \\
Individualism terhadap \\
Penggunaan E-filing dengan \\
Kepuasan Pengguna sebagai \\
Variabel Intervening (Studi \\
Empiris pada Wajib Pajak \\
UMKM di Provinsi \\
Bengkulu). Reviu Akuntansi \\
dan Bisnis Indonesia, 5(1), \\
79-90.
\end{tabular}

Link Artikel:

10.18196/rabin.v5i1.11693

\section{A B S T R A K}

\section{Latar Belakang:}

Adanya penggunaan teknologi melalui sistem elektronik diharapkan dapat mempersingkat birokrasi yang dapat meningkatkan efisiensi waktu dan mengurangi biaya dalam melaporkan SPT pajak. Dalam beberapa tahun terakhir, sektor UMKM telah berhasil menjadi penopang ekonomi di negara Indonesia. Di Indonesia terdapat 60 juta pelaku Usaha Mikro Kecil Menengah (UMKM), namun kontribusi UMKM dalam membayar dan melaporkan pajak masih sangat minim.

\section{Tujuan:}

Penelitian ini bertujuan untuk menganalisis pengaruh appearance, dan individualism terhadap penggunaan E-Filing dengan kepuasan pengguna sebagai variabel intervening.

\section{Metode Penelitian:}

Penelitian ini merupakan penelitian kuantitatif menggunakan data primer yang dikumpulkan dari Wajib Pajak UMKM di Provinsi Bengkulu dengan teknik pengambilan sample yaitu purposive sampling. Penelitian dilakukan pada 150 Wajib Pajak (UMKM) pada 10 kabupaten di Provinsi Bengkuluyang kemudian diuji dengan alat analisis SEM-PLS melalui aplikasi SmartPLS versi 3.3.2.

\section{Hasil Penelitian:}

Hasil penelitian menunjukkan bahwa appearance, individualism, dan kepuasan pengguna berpengaruh secara signifikan terhadap penggunaan eFiling. Sementara itu, kepuasan pengguna juga memediasi hubungan appearance dan individualism terhadap penggunaan e-Filing.

\section{Keterbatasan Penelitian:}

Responden pada penelitian hanya WP UMKM yang telah menggunakan e-Filing dan hanya mengambil UMKM yang ada di Provinsi Bengkulu.

Keaslian/Novelty Penelitian:

Penelitian ini merupakan kompilasi dari penelitian terdahulu dengan menambahkan kepuasan pengguna sebagai variable intervening.

(C) 2021 RAB. Published by Universitas Muhammadiyah Yogyakarta DOI: 10.18196/rabin.v5i1.11693 


\section{PENDAHULUAN}

Sebagai negara berkembang, Indonesia melakukan banyak pembangunan pada berbagai bidang dan pajak menjadi salah satu sumber utama pendapatan bagi pemerintah untuk membiayai pembangunan nasional di Indonesia dengan tujuan meningkatkan kesejahteraan masyarakat (Utama \& Setiawan, 2019). Kemajuan teknologi pada saat ini sangat bermanfaat untuk mempermudah masyarakat dalam melaksanakan kewajiban perpajakannya, seperti dalam hal pelaporan SPT pajak. Adanya penggunaan teknologi melalui sistem elektronik diharapkan dapat mempersingkat birokrasi yang dapat meningkatkan efisiensi waktu dan mengurangi biaya dalam melaporkan SPT pajak. Sari dan Erawati (2018) mengatakan bahwa e-Filing adalah sistem elektronik yang digunakan untuk sebagai sarana untuk menyampaikan Surat Pemberitahuan Tahunan (SPT) dengan memanfaatkan sistem online dan real time melalui sebuah penyedia jasa aplikasi yang sudah bekerja sama dengan Direktorat Jendral Pajak. Sistem pengarsipan pajak online hadir karena sistem pembayaran pajak manual relatif rumit dan memakan waktu (Tahar dkk, 2020). Menurut penelitian Jayatenaya dan Jati (2018) tujuan adanya penggunaan e-Filing itu sendiri yaitu meminimalisir pengeluaran dan efisiensi waktu bagi Wajib Pajak sehingga dapat melakukan persiapan, proses, dan pelaporan SPT ke kantor pajak secara cepat dan benar.

Berdasarkan laporan tahunan Direktorat Jenderal Pajak jumlah pengguna e-Filing pada tahun 2018 sebanyak 8.954.122 Wajib Pajak dan ditahun 2019 menjadi 9.152.817 Wajib Pajak, maka dapat dilihat adanya pertumbuhan yang cukup besar yaitu 8,83\% Wajib Pajak pengguna e-Filing dari tahun 2018 (DJP Pajak, 2019). Dalam beberapa tahun terakhir, sektor UMKM telah berhasil menjadi penopang ekonomi di negara Indonesia. Dirjen Pajak Suryo Utomo menyatakan ada 60 juta pelaku Usaha Mikro Kecil Menengah (UMKM), namun kontribusi UMKM dalam membayar dan melaporkan pajak masih sangat minim. Setiap tahun penerimaan pajak dari UMKM hanya berkisar antara 5 sampai 6 Triliun. Menteri Keuangan Sri Mulyani Indrawati mengatakan bahwa total penerimaan pajak nasional pada tahun 2018 mencapai Rp 1.500 triliun sedangkan kontribusi penerimaan pajak pada tahun 2018 dari sektor UMKM berada di kisaran Rp5,7 triliun atau masih sangat minim apabila dibandingkan dengan total penerimaan perpajakan nasional.

Pada tahun 2019, jumlah pelaku UMKM di Provinsi Bengkulu adalah 46.325 UMKM. Tercatat persentase UMKM di Provinsi Bengkulu mencapai 99,06 persen dari total jumlah usaha pada bidang non pertanian. Kota Bengkulu sebagai ibukota provinsi menjadi pusat pergerakan ekonomi di Provinsi Bengkulu. Pada 10 kabupaten dan kota yang berada diwilayah Provinsi Bengkulu, jumlah UMKM di kota Bengkulu mencapai 21,59 persen. Pada posisi kedua dan ketiga, Kabupaten Rejang Lebong dan Bengkulu Utara merupakan dua wilayah dengan jumlah UMKM lebih dari 10 persen di Provinsi Bengkulu. Berdasarkan hal tersebut peneliti tertarik meneliti beberapa faktor yang berpengaruh terhadap penggunaan e-filing pada Wajib Pajak UMKM di Provinsi Bengkulu dalam melaporkan pajak melalui e-Filing. Terdapat faktor yang perlu diperhatikan mengenai penggunaan e-Filing pada Wajib Pajak UMKM Provinsi Bengkulu, yaitu appearance, individualism, dan kepuasan pengguna.

Penelitian ini bertujuan untuk menguji kembali penerimaan penggunaan e-Filing oleh Wajib Pajak. Penelitian ini merupakan kompilasi dari penelitian yang dilakukan oleh Zaidi, Henderson, dan Gupta (2017); Syaninditha dan Ery Setiawan (2017); Alomari Woods, dan Sandhu (2012); Akram dkk, (2019). Penelitian ini memiliki perbedaan dengan penelitian sebelumnya yang terletak pada variabel dan model penelitian yang digunakan. Dalam penelitian ini terdapat tambahan variabel baru yaitu appearance. Serta individualism sebagai variabel independen dan pergantian variabel kepuasan pengguna sebagai variabel intervening. Berdasarkan teori TAM dan TPB variabel kepuasan akan lebih baik jika digunakan sebagai variabel intervening (Purwiyanti \& Laksito, 2020). Appearance merupakan variabel baru karena belum banyak yang meneliti pengaruh appearance terhadap penggunaan sistem e-Filing pada negara berkembang. Variabel appearance digunkan pada penelitian ini berdasarkan saran dari penelitian Nurbaiti, Susilo, dan Agusti (2016) bahwa pihak DJP secara visual untuk dapat meningkatkan kualitas sistem e-Filing agar lebih menarik, informatif dan mempermudah Wajib Pajak. Serta terdapat perubahan subjek penelitian yaitu Wajib Pajak di sektor UMKM. Diharapkan penelitian ini dapat memberikan kontribusi pada 
dua hal. Pertama, secara teoritis hasil penelitian diharapkan bisa menjadi sarana pengetahuan baru mengenai variabel apa saja yang dapat mempengaruhi penggunaan e-Filing. Kedua, secara praktis dengan adanya penelitian ini juga diharapkan akan meningkatkan penggunaan e-Filing dan membantu KPP dalam mengambil kebijakan terutama pada sektor UMKM yang ada di Provinsi Bengkulu.

\section{TINJAUAN LITERATUR DAN PERUMUSAN HIPOTESIS}

Theory of planned behavior (TPB) merupakan pengembangan dari Theory of reasoned action (TRA) oleh (Ajzen, 1991). Ada penambahan prediktor lain dalam TPB, yaitu preceived behavioral control. Menurut Hanum (2019) preceived behavioral control mengacu pada persepsi individu tentang apakah mudah atau sulit untuk melakukan perilaku tertentu. Secara umum teori TPB menyatakan bahwa semakin tinggi attitude towards behavior, subjek norm, dan preceived behavioral control yang dirasakan, maka akan semakin kuat juga niat individu untuk melakukan perilaku (Ajzen, 1991). Menurut Xie dkk ( 2017) bahwa niat perilaku untuk menggunakan kembali e-government menentukan perilaku aktual pengguna secara langsung, sedangkan niat dipengaruhi secara positif oleh Attitude towards behavior, subjek norm, dan preceived behavioral control. Adanya kebiasaan perilaku individu menggunakan e-Filing maka akan memudahkannya dalam berdapatasi (Hongyun et al., 2020 ; Harlim, 2019). TPB dapat menjadi landasan teori untuk mengetahui niat seseorang dalam menggunakan layanan sistem e-Filing (Xie dkk, 2017). Tujuan TPB dimasukkan dalam penelitian ini karena setiap individu mungkin berniat untuk menggunakan sistem e-Filing, tetapi mungkin mereka kurang paham dalam menggunakannya sehingga hal tersebut dapat menghalangi perilaku sebenarnya (Zaidi dkk, 2017).

DeLone dan McLean pada tahun (1992) mengembangkan sebuah teori yaitu Teori ISSM yang digunakan untuk mengukur keberhasilan atau efektivitas suatu sistem informasi, kesuksesan sistem tersebut dinilai dari user satisfaction (kepuasan pengguna) dan baru-baru ini diperbarui untuk memasukkan ukuran kualitas layanan karena lonjakan penggunaan teknologi informasi (Zaidi dkk, 2017). Teori ISSM memiliki enam faktor keberhasilan, yaitu kualitas sistem, kualitas informasi, penggunaan, kepuasan pengguna, dampak individu, dan dampak organisasi. Dalam versi yang diperbarui DeLone dan McLean (2003)menambahkan kualitas layanan (Tam dan Oliveira, 2017). Beberapa penelitian terkait dengan keberhasilan sistem informasi telah dilakukan oleh beberapa peneliti, termasuk (Hatta Hambali, 2020; Zaidi dkk, 2017; Al-Kofahi, Hassan, dan Mohamad (2020). Studi tersebut menunjukkan bahwa kepuasan pengguna adalah ditentukan oleh dua variabel utama, yaitu kualitas informasi dan kualitas sistem (Hatta Hambali, 2020). Kepuasan dalam menggunakan e-Filing dapat ditentukan oleh kualitas sistem e-Filing (Hatta Hambali, 2020). Sistem informasi dapat dianggap berhasil apabila berhasil memenuhi kriteria seperti kebutuhan pengguna dan sasaran organisasi. Suatu sistem e-Filing akan terus digunakan oleh pengguna apabila dapat meningkatkan kinerja dan kualitas keputusan. Penelitian Udo, Bagchi, dan Kirs (2010) menunjukkan bahwa kepuasan pengguna sebagian ditentukan oleh kualitas layanan yang mana sebagiannya bergantung pada konten situs web.

Penyampaian Surat Pemberitahuan (SPT) secara elektronik yang dilakukan secara online dan real time melalui internet disebut e-filing yang dilakukan pada website Direktorat Jenderal Pajak (http://www.pajak.go.id) atau Penyedia Jasa Aplikasi Perpajakan (PJAP). Electronic Filling atau eFiling merupakan pembaharuan dari sistem pelaporan electronik SPT (e-spt) yang diluncurkan pada 24 Januari 2005 dengan adanya Peraturan Direktur Jenderal Pajak Nomor KEP 05/PJ/2005. Pengguna e-Filing yang dijelaskan pada Undang-undang No 28 Tahun 2007 adalah Wajib Pajak. Manfaat yang bisa diperoleh dengan menggunakan sistem e-Filing aplikasi untuk menyediakan proses transparansi atau transparansi dalam pengiriman SPT untuk semua Wajib Pajak (Hanum, 2019).

Dalam teori Informasi system succes model Delone Mclean (ISSM) mengatakan bahwa keberhasilan sistem terdiri dari enam dimensi salah satunya kualitas informasi dimana di dalam kualitas informasi tersebut terdapat personalisasi (DeLone \& McLean, 1992). Appearance biasanya dapat dikategorikan dan termasuk dalam web design (Kim \& Stoel, 2004). Website design merupakan faktor penting dalam kesuksesan suatu penampilan (Flavian, Gurrea, \& Orús, 2009). 
Personalisasi disini berhubungan dengan tampilan dari sebuah konten situs web atau aplikasi web. Alomari dkk (2012) mengatakan appearance/website design merupakan daya tarik visual yang muncul sebagai faktor penting yang memengaruhi kesediaan warga untuk menggunakan layanan elektronik pemerintah.

Konten web dalam artian appearance harus dipersonalisasi, lengkap, relevan, mudah dipahami, dan dapat dipastikan jika seseorang akan menggunakan sistem tersebut secara rutin (Sørum, Normann Andersen, \& Clemmensen, 2013). Penelitian lainnya menyatakan kualitas website e-tax filling berpengaruh terhadap niat untuk tetap menggunakan (Akram dkk, 2019). Penelitian tersebut didukung oleh penelitian Al-qeisi dkk, (2014) yang menyatakan bahwa kualitas desain situs web berhubungan positif dengan penggunaan serta didukung oleh hasil penelitian Aladwani (2006) menyatakan bahwa appearance akan mempengaruhi sikap konsumen terhadap situs web. Dalam studi Lee dan Lin (2005) juga menegaskan bahwa desain situs web merupakan faktor penting dalam menentukan kualitas penggunaan layanan elektronik yang dirasakan pengguna.

\section{$\boldsymbol{H}_{i}$ : Appearance berpengaruh positif terhadap penggunaan e-Filing}

Pada teori TPB dijelaskan bahwa perilaku individu dipengaruhi oleh tiga penentu dasar yaitu sikap, norma subjektif dan persepsi kontrol perilaku Teori TPB berkaitan dengan individualism yang merupakan sikap mementingkan diri sendiri dibanding mementingkan orang lain. Dalam penelitian Zaidi, dkk, (2017) Pengguna yang individualis memiliki tingkat kepuasan yang lebih tinggi saat menggunakan sistem pajak online. Pada penelitian Udo dkk (2010) menemukan bahwa pengguna yang individualis signifikan dan mempengaruhi lebih pada kepuasan dengan kualitas informasi dan kualitas pelayanan dalam layanan online. Penelitian penelitian Zaidi dkk, (2017) menemukan bahwa individualism tidak memoderasi hubungan kualitas sistem informasi terhadap kepuasan pengguna. Janssen dkk (2013) menemukan adanya hubungan yang kuat budaya individualism pada hubungan tata kelola teknologi informasi. Pada penelitian Aparicio, Bacao, dan Oliveira (2016) Individualism berpengaruh terhadap penggunaan sistem yaitu e-learning.

\section{$\boldsymbol{H}_{2}$ : Individualism berpengaruh positif terhadap penggunaan e-Filing}

Teori DeLone dan McLean, kesuksesan sistem informasi dapat dinilai dari user satisfaction (kepuasan pengguna) dari suatu sistem dan kualitas informasi. Menurut Alomari dkk (2012) daya tarik visual muncul sebagai faktor penting yang memengaruhi masyarakat untuk bersedia menggunakan layanan elektronik pemerintah termasuk juga sistem e-Filing. Menurut hasil penelitian Ahmed (2011) variabel desain situs web memiliki pengaruh kuat pada kepuasan pengguna karena tampilannya yang menarik, mudah diakses, dan cepat untuk melakukan tugas yang diperlukan. Terdapat hasil penelitian sebelumnya yang memperkuat pernyataan tersebut yaitu oleh Alghamdi dan Rahim (2016) menyebutkan bahwa ada hubungan yang kuat antara desain situs web atau appearance dalam mempengaruhi kepuasan pengguna pada layanan e-Filing. Penelitian yang dilakukan oleh Akram dkk (2019) menegaskan bahwa kualitas situs web memainkan peran penting dalam keputusan pengguna tentang penggunaan e-Filing berkelanjutan melalui kepuasan. Pada penelitian Harlim (2019) menyatakan program e-Filing berpengaruh positif terhadap kepatuhan wajib pajak melalui kepuasan kualitas pelayanan. Dalam pernyataan tersebut dapat dikatakan bahwa kualitas website yang dapat berupa penampilan dapat mempengaruhi kepuasan serta kepuasan adalah faktor yang mempengaruhi penggunaan suatu sistem.

\section{$\boldsymbol{H}_{3}$ : Appearance berpengaruh positif terhadap penggunaan e-Filing dengan kepuasan pengguna sebagai variabel intervening}


Pada TPB niat adalah salah satu faktor terjadinya suatu tindakan yang dipengaruhi oleh faktor pribadi dan pengaruh sosial serta berpengaruh terhadap niat perilaku individu yang menyebabkan perilaku. Hastuti dkk (2014) meneliti implementasi sistem e-Filing dengan menggunakan TPB dengan hasil penelitian yang menunjukkan bahwa niat warga negara Indonesia untuk menggunakan fasilitas e-filling untuk melaporkan pendapatan pajak tahunannya bergantung pada sikap dan kontrol mereka terhadap sistem tersebut. Dalam penelitian Zaidi dkk, (2017) menyebutkan bahwa pengguna yang individualis memiliki tingkat kepuasan yang lebih tinggi saat menggunakan sistem etax. Namun pada penelitian Zaidi dkk, (2017) yang meneliti pengaruh kualitas sistem informasi terhadap kepuasan pengguna yang dimoderasi oleh individualism hasilnya tidak didukung sehingga individualism diadopsi sebagai variabel independen.

Pada hasil penelitian Udo dan Bagchi (2011) menyatakan semakin tinggi tingkat individualisme yang dianut dari pengguna online, semakin besar pengaruh Information System Quality pada kepuasan pengguna. Seseorang yang individualis cenderung menggunakan teknologi karena lebih efektif dan menguntungkan bagi mereka. Penelitian Srite dan Karahanna (2006) menemukan bahwa nilai-nilai budaya nasional yang dianut mempengaruhi penerimaan individu terhadap teknologi. Pengguna yang individualis cenderung memiliki tingkat kepuasan yang lebih tinggi dalam menggunakan e-Filing.

$\boldsymbol{H}_{4}$ : Individualism berpengaruh positif terhadap penggunaan e-Filing dengan kepuasan pengguna sebagai variabel intervening

Teori DeLone dan McLean, kesuksesan sistem informasi dapat dinilai dari user satisfaction (kepuasan pengguna) dari suatu sistem dan kualitas informasi. Kepuasan pengguna atau user satisfaction menunjukkan seberapa jauh pemakai puas dan percaya pada sistem informasi yang disediakan untuk memenuhi kebutuhan mereka (Suaryana, Damayanthi, \& Merkusiwati, 2017). Penelitian DeLone dan McLean bertujuan untuk mengetahui kesuksesan dalam sistem informasi termasuk juga kepuasan pengguna (Sorum et al., 2013). Semakin tinggi kepuasan pengguna maka akan meningkatkan penggunaan e-Filing, hasil penelitian Zaidi dkk, (2017) Noviandini (2012), dan Harlim (2019) menyatakan bahwa kepuasan pengguna berpengaruh terhadap penggunaan e-Filing.

\section{$\boldsymbol{H}_{s}$ :Kepuasan pengguna berpengaruh positif terhadap penggunaan e-Filing}

\section{METODE PENELITIAN}

Objek penelitian adalah UMKM di Provinsi Bengkulu sedangkan Wajib Pajak UMKM yang telah menggunakan e-Filing dalam menyampaikan SPT Tahunannya dan telah terdaftar di KPP Pratama Bengkulu merupakan subjek pada penelitian ini. Penelitian ini merupakan penelitian kuantitatif dengan sumber data primer hasil dari penyebaran kuesioner pada Wajib Pajak UMKM atau responden di Provinsi Bengkulu. Penyebaran kuesioner dilakukan untuk mengetahui pengaruh dari appearance dan individualism terhadap penggunaan e-Filing serta kepuasan pengguna sebagai variabel intervening. Teknik pengambilan sampel pada penelitian ini adalah purposive sampling. Metode purposive sampling ini adalah metode pengambilan sampel yang dipilih sesuai dengan persyaratan yang ditentukan oleh peneliti. Sampel yang digunakan pada penelitian ini memiliki kriteria yaitu merupakan Wajib Pajak UMKM beromzet kurang dari 4,8 miliar per tahun yang berlokasi di Provinsi Bengkulu serta telah menggunakan sistem e-Filing dalam melaporkan SPT.

Teknik pengumpulan data menggunakan metode survei yaitu dengan membagikan kuesioner kepada responden. Responden memilih tingkat ketidak setujuan dan kesetujuannya atas jawaban pernyataan yang diberikan mengenai appearance dan individualism terhadap penggunaan e-Filing serta kepuasan pengguna sebagai variabel intervening. Kuesioner yang digunakan diadopsi dari Alomari dkk (2012); Zaidi dkk (2017); Syaninditha dan Ery Setiawan (2017) dengan modifikasi. 
Skala pengukuran menggunakan model skala likert 1 sampai 5 mulai dari sangat tidak setuju (1), tidak setuju (2), netral (3), setuju (4), dan sangat setuju (5). Pengolahan data dan analisis hubungan antar konstruk pada penelitian ini menggunakan aplikasi SmartPLS versi 3.3.2.

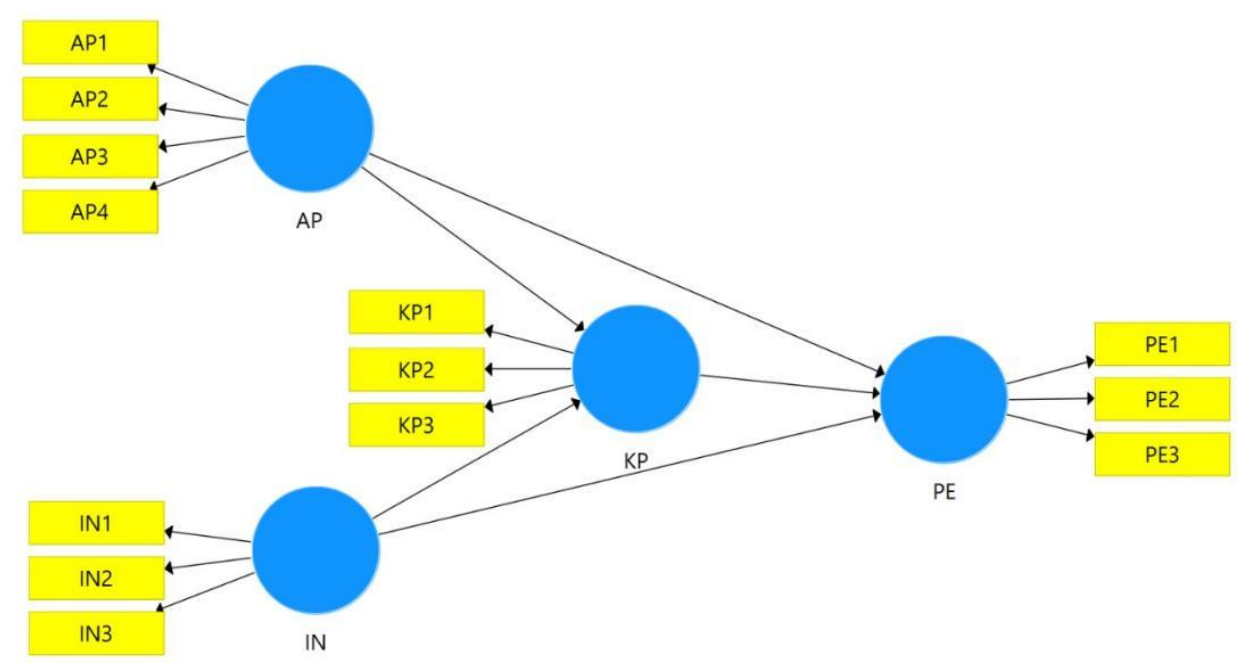

Gambar 1 Model Penelitian SEM-PLS

\section{HASIL DAN PEMBAHASAN}

Kuesioner dibagikan kepada Wajib Pajak UMKM pada 10 Kabupaten dan Kota yang terletak di Provinsi Bengkulu, yaitu Kabupaten Bengkulu Selatan, Kabupaten Bengkulu Tengah, Kabupaten Bengkulu Utara, Kabupaten Kaur, Kabupaten Kepahiang, Kabupaten Lebong, Kabupaten Mukomuko, Kabupaten Rejang Lebong, Kabupaten Seluma, Kota Bengkulu. Peneliti telah menyebarkan kuesioner sebanyak 170 kuesioner kepada responden di setiap Kabupaten/Kota pada Wajib Pajak UMKM Provinsi Bengkulu. Penyebaran kuesioner dilakukan pada tanggal 18 Agustus 2020 sampai 18 September 2020. Jumlah Kuesioner yang dibagikan dalam penelitian adalah sebanyak 170 kuesioner dan sebanyak 156 Kuesioner kembali dan kuesioner yang dapat diolah sebanyak 150 kuesioner. Kuesioner yang bisa diolah selanjutnya ditabulasikan berdasarkan karakteristik dan variabel penelitian. Karakteristik responden yaitu mencakup jenis kelamin responden, pekerjaan responden, usia responden, jenis usaha, bentuk usaha dan lama usaha responden. Berdasarkan data yang diperoleh dapat didapatkan hasil karakteristik responden adalah laki-laki sebanyak 85 responden, usia 51 tahun ke atas sebanyak 52 responden, pekerjaan sebagai wiraswasta sebanyak 120 responden, jenis usaha perdagangan sebanyak 80 responden, bentuk usaha orang pribadi sebanyak 130 responden dan sebanyak 78 responden telah menjalankan usaha selama $>10$ tahun.

Tabel 1 Hasil Uji Statistik Deskriptif

Std.

\begin{tabular}{lcccccc} 
& N & Range & Minimum & Maximum & Mean & Deviation \\
\hline Appearance & 150 & 14 & 6 & 20 & 14.35 & 3.089 \\
Individualism & 150 & 12 & 3 & 15 & 8.82 & 2.523 \\
Kepuasan Pengguna & 150 & 12 & 3 & 15 & 11.27 & 2.363 \\
Penggunaan E-Filing & 150 & 11 & 4 & 15 & 11.75 & 2.308 \\
Valid N (listwise) & 150 & & & & & \\
\hline
\end{tabular}


Pada Tabel 1 jumlah data yang diolah untuk variabel appearance terdiri dari 150 data. Nilai minimal dari data tersebut adalah 6 dan nilai maksimalnya adalah 20 dengan jarak atau range yaitu 14 dengan rata-rata 14,35 dan standar deviasi 3,089. Jumlah data yang diolah untuk variabel individualism terdiri dari 150 data. Nilai minimal dari data tersebut adalah 3 dan nilai maksimalnya adalah 15 dengan jarak atau range sebesar 12 dengan rata-rata sebesar 8,82 dan standar deviasi sebesar 2,523. Jumlah data yang diolah untuk variabel kepuasan pengguna terdiri dari 150 data. Nilai minimal dari data yaitu 3 dan nilai maksimalnya 15 dengan jarak atau range yaitu 12, dengan rata-rata sebesar 11,27 dan standar deviasi sebesar 2,363. Jumlah data yang diolah untuk variabel penggunaan e-Filing terdiri dari 150 data. Nilai minimal dari data tersebut adalah 4 dan nilai maksimalnya adalah 15 dengan jarak atau range sebesar 11, dengan rata-rata sebesar 11,75 dan standar deviasi sebesar 2,308 .

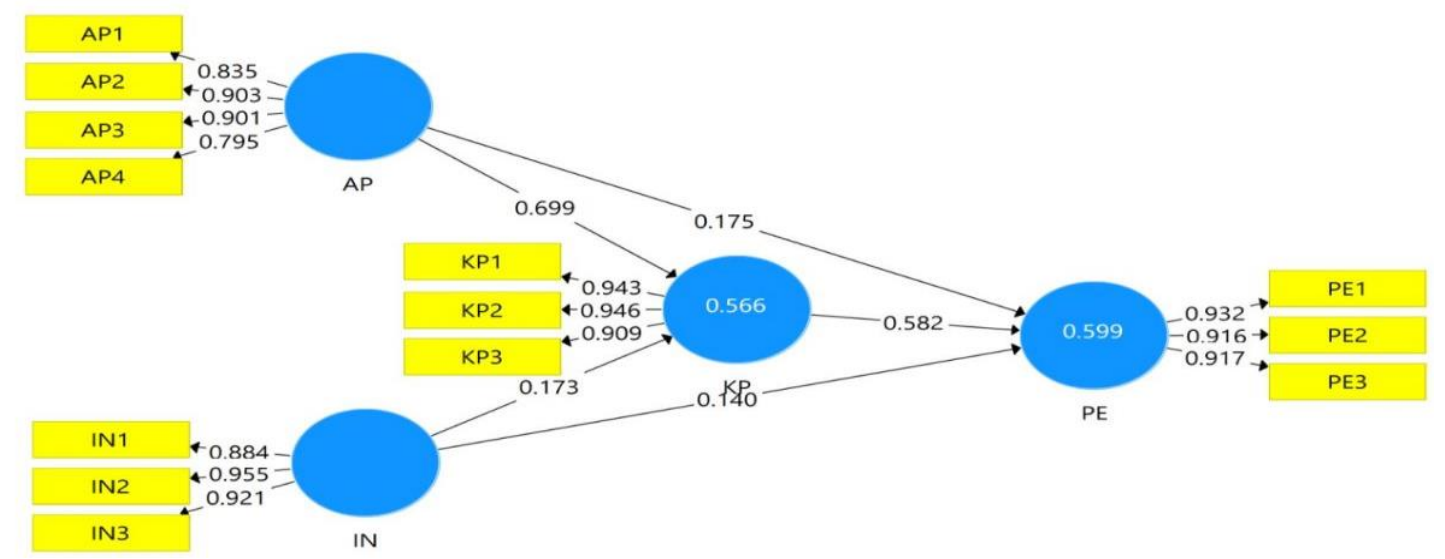

Gambar 2 Tampilan Output Model Pengukuran PLS

Evaluasi model pengukuran bertujuan untuk menguji kualitas model pengukuran, yaitu validitas dan reliabilitas data konstruk. Pengujian validitas dilakukan dua kali, yaitu validitas konvergen dan validitas diskriminan. Indikator pengujian validitas konvergen dapat dilihat dari dua tabel, yaitu outer loading dan nilai Average Variance Extracted (AVE). Indikator konstruk dikatakan valid jika outer loading memiliki nilai setiap konstruk harus lebih besar dari 0,7 dan nilai Average Variance Extracted (AVE) diatas 0,50 (Abdillah dan Jogiyanto, 2015). Berdasarkan tabel 2 hasil loading setiap indikator pada variabel menunjukkan angka $>0,70$ dan nilai Average Variance Extracted >0,5 untuk setiap variabel. Dengan demikian, seluruh indikator valid.

Tabel 2 Outer Loading dan Average Variance Extracted

\begin{tabular}{llll}
\hline Model Construct & Measurement Item & Loading & $\begin{array}{l}\text { Average Varince } \\
\text { Extracted }\end{array}$ \\
\hline Appearance & Appearance1 & 0,835 & 0,739 \\
& Appearance2 & 0,903 & \\
& Appearance3 & 0,901 & \\
Individualism & Appearance4 & 0,795 & 0,847 \\
& Individualism1 & 0,884 & \\
Kepuasan Pengguna & Individualism2 & 0,995 & \\
& Individualism3 & 0,921 & \\
& KepuasanPengguna1 & 0,943 & \\
Penggunaan E-Filing & KepuasanPengguna2 & 0,946 & \\
& KepuasanPengguna3 & 0,909 & 0,850 \\
& PenggunaanE-Filing1 & 0,932 & \\
\hline
\end{tabular}


Indikator pengujian validitas diskriminan adalah Akar AVE yang terlihat dalam tabel Fornell Larcker pada Algoritma PLS Report. Nilai yang ditunjukkan untuk setiap variabel seharusnya lebih besar dari nilai hubungan antar variabel. Selain itu, pengujian validitas diskriminan juga dapat dilihat dari tabel cross loading. Cross loading menunjukkan nilai antara konstruk dan indikatornya. Nilai antara konstruk dan indikatornya harus lebih besar dibanding nilai konstruk tersebut dengan indikator konstruk lain sehingga konstruk tersebut mampu memprediksi indikatornya lebih baik dibanding dengan indikator konstruk lain. Berdasarkan tabel 3, Nilai yang ditunjukkan setiap variabel lebih besar dari nilai hubungan antar variabel dan pada Tabel 4 nilai indikator setiap konstuk untuk seluruh variabel menunjukkan nilai > 0,7. Artinya, setiap indikator penelitian ini adalah valid.

Tabel 3 Fornell-Larcer

\begin{tabular}{lllll}
\hline & Appearance & Individualism & $\begin{array}{l}\text { Kepuasan } \\
\text { Pengguna }\end{array}$ & $\begin{array}{l}\text { Penggunaan E- } \\
\text { Filing }\end{array}$ \\
\hline Appearance & 0,860 & & & \\
Individualism & 0,195 & 0,920 & & \\
Kepuasan Pengguna & 0,733 & 0,309 & 0,933 & \\
Penggunaan E-Filing & 0,629 & 0,354 & 0,754 & 0,922 \\
\hline
\end{tabular}

Tabel 4 Cross Loading

\begin{tabular}{|c|c|c|c|c|}
\hline & Appearance & Individualism & $\begin{array}{l}\text { Kepuasan } \\
\text { Pengguna }\end{array}$ & $\begin{array}{c}\text { Penggunaan } \\
\text { e-Filing }\end{array}$ \\
\hline Appearance1 & 0,835 & 0,141 & 0,552 & 0,493 \\
\hline Appearance 2 & 0,903 & 0,165 & 0,619 & 0,578 \\
\hline Appearance 3 & 0,901 & 0,157 & 0,702 & 0,597 \\
\hline Appearance 4 & 0,795 & 0,207 & 0,635 & 0,485 \\
\hline Individualism 2 & 0,134 & 0,884 & 0,244 & 0,233 \\
\hline Individualism 3 & 0,236 & 0,955 & 0,324 & 0,383 \\
\hline Individualism 4 & 0,151 & 0,921 & 0,274 & 0,342 \\
\hline Kepuasan_Penggunal & 0,678 & 0,354 & 0,943 & 0,743 \\
\hline Kepuasan_Pengguna 2 & 0,698 & 0,313 & 0,946 & 0,698 \\
\hline Kepuasan_Pengguna 3 & 0,676 & 0,191 & 0,909 & 0,667 \\
\hline Penggunaan_E-Filing1 & 0,642 & 0,310 & 0,744 & 0,932 \\
\hline Penggunaan_E-Filing 2 & 0,518 & 0,339 & 0,643 & 0,916 \\
\hline Penggunaan_E-Filing 3 & 0,573 & 0,333 & 0,692 & 0,917 \\
\hline
\end{tabular}

Pengujian reliabilitas pada penelitian ini menggunakan Cronbachs Alpha dan Composite Reliability. Uji realibilitas dapat dilihat dari nilai cronbachs alpha $>0,7$ dan nilai Composite reliability harus $>0,7$ (Abdilah \& Hartono, 2015). Berdasarkan tabel 5 menunjukkan bahwa nilai Cronbachs Alpha diatas 0,7 dan Composite Reliability diatas 0,7 untuk seluruh konstruk pada penelitian ini. Dapat disimpulkan, seluruh konstruk reliabel.

Tabel 5 Cronbach Alpha dan Composite Reliability

\begin{tabular}{llll}
\hline & $\begin{array}{l}\text { Cronbach's } \\
\text { Alpha }\end{array}$ & $\begin{array}{l}\text { Composite } \\
\text { Reliability }\end{array}$ & Keterangan \\
\hline Individualism & 0,881 & 0,919 & Reliabel \\
Appearance & 0,911 & 0,943 & Reliabel \\
$\begin{array}{l}\text { Penggunaan } \\
\text { E-Filing }\end{array}$ & 0,925 & 0,953 & Reliabel \\
$\begin{array}{l}\text { Kepuasan } \\
\text { Pengguna }\end{array}$ & 0,912 & 0,944 & Reliabel \\
\hline
\end{tabular}


Tabel 6 menunjukkan bahwa nilai Adjusted $R 2$ kepuasan pengguna sebesar 0,560 yang artinya $56 \%$ variabel kepuasan pengguna dipengaruhi oleh variabel independen, dan $44 \%$ dijelaskan oleh variabel lain. Kemudian nilai Adjusted $R 2$ penggunaan e-Filing sebesar 0.591 yang artinya $59 \%$ variabel dari penggunaan e-Filing dipengaruhi oleh variabel independennya. Hal ini berarti $41 \%$ dari variabel dependen dijelaskan oleh faktor lain yang tidak diukur dalam penelitian ini.

Tabel 6 Nilai Adjusted R-Square

\begin{tabular}{ccc}
\hline & R Square & Adjusted R Square \\
\hline Kepuasan Pengguna & 0,566 & 0,560 \\
Penggunaan E-Filing & 0,599 & 0,591 \\
\hline
\end{tabular}

Tabel 7 Path Coefficient

\begin{tabular}{|c|c|c|c|c|}
\hline Variabel & Original Sample & t-statistik & $p$-values & Simpulan \\
\hline $\begin{array}{l}\text { Appearance } \rightarrow \\
\text { Penggunaan } \text { E-Filing }\end{array}$ & 0,175 & 2,257 & $0,024^{* *}$ & Terdukung \\
\hline $\begin{array}{l}\text { Penggunaan } \text { E-Filing } \\
\text { Individualism } \rightarrow \\
\text { Pengounaan } \text { E-Filing. }\end{array}$ & 0,140 & 2,593 & $0,010^{* *}$ & Terdukung \\
\hline $\begin{array}{l}\text { Penggunaan } \text { E-Filing } \\
\text { Appearance } \rightarrow \\
\text { Kepuasan Pengguna } \\
\rightarrow \text { Penggunaan } E \text { - } \\
\text { Filing. }\end{array}$ & 0,407 & 7.354 & $0,000^{* *}$ & Terdukung \\
\hline $\begin{array}{l}\text { Individualism } \rightarrow \\
\text { Kepuasan Pengguna } \\
\rightarrow \text { Penggunaan } E- \\
\text { Filing }\end{array}$ & 0,101 & 2,927 & $0,004^{* *}$ & Terdukung \\
\hline $\begin{array}{l}\text { Kepuasan Pengguna } \\
\rightarrow \text { Penggunaan } E \text { - } \\
\text { Filing }\end{array}$ & 0,582 & 7,608 & $0,000^{* *}$ & Terdukung \\
\hline
\end{tabular}

Terdapat tiga indikator yang harus diperhatikan sebagai kriteria pengujian hipotesis, yaitu original sample, t-statistic, dan p-values. Original sample digunakan untuk melihat arah dari pengujian hipotesis. t-statistic dan p-values digunakan untuk menunjukkan signifikansi. Jika hipotesis memiliki arah (one-tiled) maka nilai t-statistics harus $>1,64$ dan jika hipotesis tidak memiliki arah (two-tiled) maka nilai t-statistic harus $>1,96$ dan $\mathrm{p}$ value $<0,05$. Nilai Original sample, t-statistic, dan p-values. Dari tabel 7, dapat disimpulkan seluruh hipotesis diterima.

\section{KESIMPULAN}

Penelitian ini menguji dan menganalisis faktor-faktor yang berpengaruh terhadap penggunaan E-Filing pada Wajib Pajak UMKM di Provinsi Bengkulu. Faktor-faktor yang diteliti pada penelitian ini yaitu, appearance dan individualism. Pada penelitian ini kepuasan pengguna digunakan sebagai variabel pemediasi. Berdasarkan pengujian dan analisis yang telah dilakukan appearance berpengaruh terhadap penggunaan e-Filing, Individualism berpengaruh terhadap penggunaan eFiling, Kepuasan pengguna memediasi hubungan appearance terhadap penggunaan e-Filing, kepuasan pengguna memediasi hubungan individualism terhadap penggunaan e-Filing, Kepuasan pengguna berpengaruh positif terhadap penggunaan e-Filing. Penelitian selanjutnya diharapkan menambah jumlah responden penelitian serta menambah variasi responden atau dapat menggunakan opsi lain dalam penelitian supaya lebih objektif, misalnya dengan menggunakan metode wawancara. 


\section{DAFTAR PUSTAKA}

Abdilah, W., \& Hartono, J. (2015). Partial Least Square (PLS) alternatif Structural Equation Modeling (SEM) dalam penelitian bisnis. Yogyakarta: Penerbit Andi.

Ahmed, K. (2011). Online service quality and customer satisfaction: A case study of Bank Islam Malaysia berhad. MPRA Paper. Diakses dari https://mpra.ub.uni-muenchen.de/30782/

Ajzen, I. (1991). The theory of planned behavior. Organizational Behavior and Human Decision Processes, 50(2), 179-211. https://doi.org/10.1016/0749-5978(91)90020-t

Akram, M. S., Malik, A., Shareef, M. A., \& Awais Shakir Goraya, M. (2019). Exploring the interrelationships between technological predictors and behavioral mediators in online tax filing: The moderating role of perceived risk. Government Information Quarterly, 36(2), 237 251. https://doi.org/10.1016/j.giq.2018.12.007

Aladwani, A. M. (2006). An empirical test of the link between web site quality and forward enterprise integration with web consumers. Business Process Management Journal, 12(2), 178-190. https://doi.org/10.1108/14637150610657521

Alghamdi, A., \& Rahim, M. (2016). Development of a Measurement Scale for user satisfaction with e-tax systems in Australia. Lecture Notes in Computer Science, 64-83. https://doi.org/10.1007/978-3-662-53416-8_5

Al-Kofahi, M. K., Hassan, H., \& Mohamad, R. (2020). Information systems success model: A review of literature. International Journal of Innovation, Creativity and Change, 12(10), 104110. Diakses dari https://www.ijicc.net/images/vol12/iss10/121013 Kofahi 2020 E R.pdf

Alomari, M., Woods, P., \& Sandhu, K. (2012). Predictors for e-government adoption in Jordan. Information Technology \& People, 25(2), 207-234. https://doi.org/10.1108/09593841211232712

Al-Qeisi, K., Dennis, C., Alamanos, E., \& Jayawardhena, C. (2014). Website design quality and usage behavior: Unified Theory of Acceptance and Use of Technology. Journal of Business Research, 67(11), 2282-2290. https://doi.org/10.1016/j.jbusres.2014.06.016

Aparicio, M., Bacao, F., \& Oliveira, T. (2016). Cultural impacts on e-learning systems' success. Internet and Higher Education, 31, 58-70. https://doi.org/10.1016/j.iheduc.2016.06.003

DeLone, W. H., \& McLean, E. R. (1992). Information systems success: The quest for the dependent variable. Information Systems Research, 3(1), 60-95. https://doi.org/10.1287/isre.3.1.60

DeLone, W. H., \& McLean, E. R. (2003). The DeLone and McLean model of information systems success: A ten-year update. Journal of Management Information Systems, 19(4), 9-30. https://doi.org/10.1080/07421222.2003.11045748

Flavian, C., Gurrea, R., \& Orús, C. (2009). Web design: a key factor for the website success.Journal of Systems and Information Technology, 11(2), 168-184. https://doi.org/10.1108/13287260910955129

Hanum, L. (2019). Taxpayers' perception using e-filling system. Proceedings of the Annual International Conference of Business and Public Administration (AICoBPA 2018). https://doi.org/10.2991/aicobpa-18.2019.29

Hanum, L. (2019). Taxpayers' perceptions towards e-filing system application: A decomposed theory of planned behavior (dtpb) approach. Profit, 13(01), 1-17. https://doi.org/10.21776/ub.profit.2019.013.01.1

Harlim, A. (2019). Pengaruh penerapan E-SPT, E-Filling, dan E-Billing terhadap tingkat kepuasan dan dampaknya pada kepatuhan wajib pajak. Prosiding Seminar Nasional Pakar.

Hastuti, S., Suryaningrum, D., Susilowati, L., \& Muchtolifah, M. (2014). Implementation of decomposed theory of planned behavior on the adoption of e-filling systems taxation policy in Indonesia. Expert Journal of Business and Management, 2(1), 1-8. Diakses dari https://business.expertjournals.com/23446781-201/

Hatta Hambali, A. J. (2020). The success of e-filing adoption during COVID 19 pandemic: The role of collaborative quality, user intention, and user satisfaction. Journal of Economics, Business, \& Accountancy Ventura, 23(1). https://doi.org/10.14414/jebav.v23i1.2233 
Janssen, L. A., Luciano, E. M., \& Gregianin Testa, M. (2013). The influence of organizational culture on IT Governance: Perception of a group of IT managers from Latin American companies. Proceedings of the Annual Hawaii International Conference on System Sciences, 4485-4494. https://doi.org/10.1109/HICSS.2013.527

Jayatenaya, I., \& Jati, K. (2018). Pengaruh persepsi kegunaan, persepsi kemudahan, dan pengalaman menggunakan sistem E-Filling pada penggunaan sistem E-SPTPD. E-Jurnal Akuntansi, 23(3), 2285-2310. https://doi.org/10.24843/eja.2018.v23.i03.p25

Kim, S., \& Stoel, L. (2004). Apparel retailers: website quality dimensions and satisfaction. Journal of Retailing and Consumer Services, 11(2), 109-117. https://doi.org/10.1016/s09696989(03)00010-9

Lee, G., \& Lin, H. (2005). Customer perceptions of e-service quality in online shopping. International Journal of Retail \& Distribution Management, 33(2), 161-176. https://doi.org/10.1108/09590550510581485

Noviandini, N. C. (2012). pengaruh persepsi kebermanfaatan, persepsi kemudahan penggunaan, dan kepuasan wajib pajak terhadap penggunaan e-filing bagi wajib pajak di Yogyakarta. Nominal, Barometer Riset Akuntansi dan Manajemen, 1(1), 15-22. https://doi.org/10.21831/nominal.v1i1.988

Nurbaiti, E., Susilo, H., \& Agusti, R. R. (2016). Pengaruh implementasi sistem elektronik bagi wajib

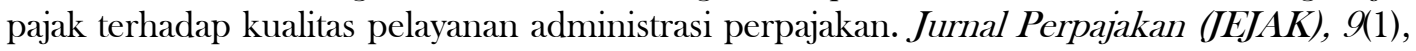
$1-9$. Diakses dari http://perpajakan.studentjournal.ub.ac.id/index.php/perpajakan/article/view/269

Peraturan Direktur Jenderal Pajak Nomor. (2005). Peraturan Direktur Jenderal Pajak Nomor KEP $05 / \mathrm{PJ} / 2005$.

Purwiyanti, D. W., \& Laksito, H. (2020). Pengaruh persepsi kemudahan, kebermanfaatan dan kepuasan penggunaan e-filing terhadap kepatuhan wajib pajak orang pribadi (Studi pada KPP Pratama Candisari Semarang). Diponegoro Journal of Accounting, $9(2)$. Diakses dari https://ejournal3.undip.ac.id/index.php/accounting/article/view/27550

Sari, R. R., \& Erawati, T. (2018). Pengaruh penerapan efiling terhadap kepatuhan wajib pajak dalam menyampaikan SPT tahunan dengan kepuasan kualitas pelayanan sebagai variabel intervening. Jurnal Akuntansi, 6(1), 1-10. https://doi.org/10.24964/ja.v6i1.427

Sørum, H., Normann Andersen, K., \& Clemmensen, T. (2013). Website quality in government. Transforming Government: People, Process and Policy, 7(3), 322-341. https://doi.org/10.1108/tg-10-2012-0012

Srite, M., \& Karahanna, E. (2006). The role of espoused national cultural values in technology acceptance. MIS Quarterly, 30(3), 679-704. https://doi.org/10.2307/25148745

Suaryana, I. G. N. A., Damayanthi, E., \& Merkusiwati, L. (2017). Kualitas dan kepuasan pengguna terhadap sistem informasi akademik berbasis web. Jurnal Ilmiah Akuntansi Dan Bisnis, 11(2), 84-90. https://doi.org/10.24843/jiab.2016.v11.i02.p03

Syaninditha, S., \& Ery Setiawan, P. (2017). Pengaruh persepsi kegunaan, persepsi kemudahan, faktor sosial, dan kondisi yang memfasilitasi terhadap minat penggunaan e-filing. E-Jurnal Akuntansi, 21(1), 86-115. Diakses dari https://ojs.unud.ac.id/index.php/Akuntansi/article/view/28724

Tahar, A., Riyadh, H. A., Sofyani, H., \& Purnomo, W. E. (2020). Perceived ease of use, perceived usefulness, perceived security and intention to use e-filing: The role of technology readiness. The Journal of Asian Finance, Economics and Business, 7(9), 537-547. https://doi.org/10.13106/jafeb.2020.vol7.no9.537

Tam, C., \& Oliveira, T. (2017). Understanding mobile banking individual performance. Internet Research, 27(3), 538-562. https://doi.org/10.1108/intr-05-2016-0117

Udo, G. J., Bagchi, K. K., \& Kirs, P. J. (2010). An assessment of customers' e-service quality perception, satisfaction and intention. International Journal of Information Management, 30(6), 481-492. https://doi.org/10.1016/j.ijinfomgt.2010.03.005 
Udo, G., \& Bagchi, K. (2011). Understanding the Influence of Espoused Culture on Acceptance of Online Services in a Developing Country. The Journal of Information Technology Theory and Application, 12(3). Diakses dari https://aisel.aisnet.org/jitta/vol12/iss2/3/

Utama, P. N. P., \& Setiawan, P. E. (2019). Pengaruh dimensi keadilan, sosialisasi pajak, sanksi pajak, penghasilan wajib pajak dan pemeriksaan pajak terhadap kepatuhan WPOP UMKM. E-Jurnal Akuntansi, 28(2), 1550. https://doi.org/10.24843/eja.2019.v28.i02.p28

Xie, Q., Song, W., Peng, X., \& Shabbir, M. (2017). Predictors for e-government adoption: integrating TAM, TPB, trust and perceived risk. The Electronic Library, 35(1), 2-20. https://doi.org/10.1108/el-08-2015-0141

Zaidi, S. K. R., Henderson, C. D., \& Gupta, G. (2017). The moderating effect of culture on e-filing taxes: evidence from India. Journal of Accounting in Emerging Economies, 7(1), 134-152. https://doi.org/10.1108/jaee-05-2015-0038 